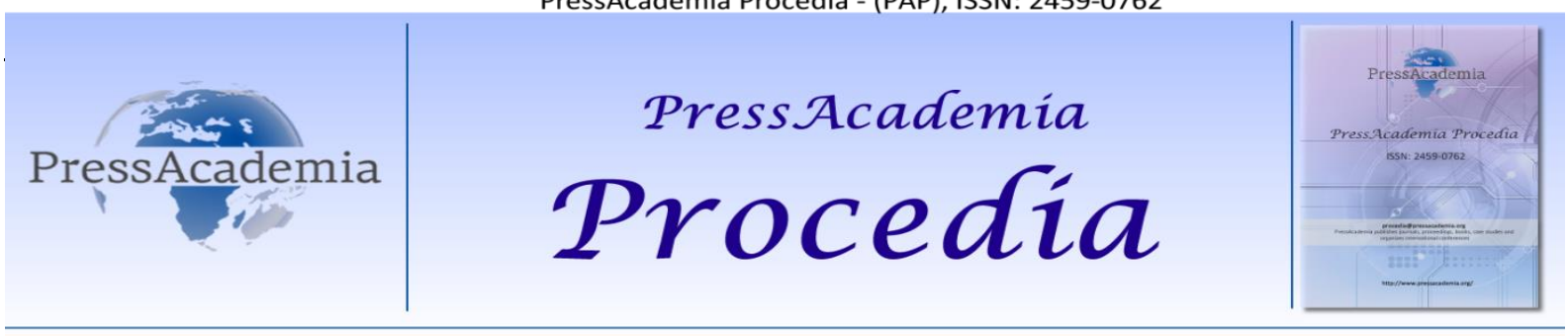

Global Business Research Congress (GBRC), May 24-25, 2017, Istanbul, Turkey

\title{
A STUDY ON EVALUATING PERCEIVED SERVICE QUALITY IN PUBLIC TRANSPORTATION WITH FUZZY ELECTRE I METHOD
}

\author{
DOI: 10.17261/Pressacademia.2017.406 \\ PAP-GBRC-V.3-2017(21)-p.218-221
}

\section{Sedat Belbag ${ }^{1}$, Aybegum Gungordu Belbag ${ }^{2}$}

${ }^{1}$ Gazi University, School of Economics and Administrative Sciences, Ankara, Turkey. sedatbelbag@gazi.edu.tr

${ }^{2}$ Bartin University, School of Economics and Administrative Sciences, Bartin, Turkey. aybegum.gungordu@gmail.com

To cite this document

Belbag, S., A. G. Belbag (2017). A study on evaluating perceived service quality in public transportation with fuzzy electre I method. PressAcademia Procedia (PAP), V.3, p.218-221

Permemant link to this document: http://doi.org/10.17261/Pressacademia.2017.406

Copyright: Published by PressAcademia and limited licenced re-use rights only.

\begin{abstract}
The measurement and evaluation of perceived service quality has been a constantly debated topic in the literature. There have been numerous papers dealing with how perceived service quality should be evaluated. On the other hand, limited number of measurable data complicates the evaluation of perceived service quality. This study proposes Fuzzy ELECTRE I method to evaluate the perceived service quality of the public transportation system. In first step of the study, a SERVQUAL based questionnaire has been designed to collect data for measuring transportation service quality of the metro system in Ankara. In the second step, assessments of the participants have been collected to rate alternatives and criteria. The collected data has been used for evaluating each alternative with respect to the performance score with the Fuzzy ELECTRE I method. Fuzzy ELECTRE I provides a consistent evaluation among alternatives under limited and qualitative information. In this study, we adapt Awasthi et al. (2011)'s SERVQUAL based questionnaire. The five lines in Ankara metro system has been evaluated with Fuzzy ELECTRE I.
\end{abstract}

Keywords: Fuzzy ELECTRE I, public transportation, perceived service quality, multi-criteria decision making methods, SERVQUAL.

JEL Codes: M10, M30, M31

\section{KAMU TAŞIMACILIĞINDA ALGILANAN HIZMET KALITESINNIN BULANIK ELECTRE I YÖNTEMIYLE DEĞERLENDIRIILMESI ÜZERINE BIR ÇALIŞMA}

\section{ÖZET}

Algılanan hizmet kalitesinin ölçülmesi ve değerlendirilmesi literatürde sıkça tartışılan önemli bir konudur. Algılanan hizmet kalitesinin nasıl ölçülmesi gerektiğini ilgilenen birçok çalışma mevcuttur. Diğer yandan, ölçülebilir nitelikteki verilerin azlı̆ı algılanan hizmet kalitesinin değerlendirilmesini güçleştirir. Bu çalışma, bir kamu taşımacılık sisteminin algılanan hizmet kalitesini değerlendirmek için Bulanık ELECTRE I yöntemini önermektedir. Çalışmanın ilk aşamasında, Ankara ili metro sisteminin algılanan hizmet kalitesini ölçen verileri toplamak için SERVQUAL yöntemini temel alan bir anket oluşturulmuştur. ikinci aşamada, katılımcılardan alternatifler ve hizmet kalite kriterleri ile ilgili görüşleri toplanmıştır. Toplanan veri, Bulanık ELECTRE I yöntemiyle her bir alternatifin performans puanına göre değerlendirilmesi için kullanılmıştır. Bulanık ELECTRE I gerekli bilginin kısıtlı ve nitel olduğu durumlarda alternatifler arasında tutarlı bir değerlendirme yapılabilmesini sağlamaktadır. Bu çalışmada, Awasthi vd. (2011)'nin SERVQUAL temelli ölçeğinden faydalanılmıştır. Bulanık ELECTRE I yöntemi ile Ankara metro sisteminde yer alan beş farklı hat değerlendirilmiştir.

Anahtar Kelimeler: Bulanık Electre I, kamu taşımacılığı, algılanan hizmet kalitesi, çok kriterli karar verme yöntemleri, SERVQUAL JEL Kodları: M10, M30, M31 


\section{GiRiş}

Algılanan hizmet kalitesinin ölçülmesi ve değerlendirilmesi literatürde sıkça tartışılan önemli bir konudur. Algılanan hizmet kalitesinin nasıl ölçülmesi gerektiğiyle ilgilenen birçok çalışma mevcuttur (Gronroos 1988; Lee vd. 2000; Brady ve Cronin 2001; Hu ve Jen 2006; Lai ve Chen 2011; de Oña vd. 2013). Diğer yandan, ölçülebilir nitelikteki verilerin azlığı algılanan hizmet kalitesinin değerlendirilmesini güçleştirir. Algılanan hizmet kalitesinin çok kriterli karar verme yöntemleri (ÇKKY) ile değerlendirilmesi ise literatürde çeşitli çalışmalarda (Liou ve Tzeng 2007; Liou vd. 2011; Awasthi vd., 2011; Altuntas vd. 2012; Büyüközkan ve Çifçi 2012; Liu vd. 2013; Ay Türkmen ve Bildik, 2015) yer almaktadır. Bu çalışmalardan içerisinde Liou ve Tzeng 2007; Awasthi vd., 2011; Liou vd. 2011; Ay Türkmen ve Bildik, 2015 kamu taşımacılı̆ıındaki algılanan hizmet kalitesini belirlemeye odaklanmıştır. Çalışmalar kamu taşımacılı̆̆ını, otobüsle yolcu taşımacılığı (Ay Türkmen ve Bildik, 2015), hava yolu taşımacılığı (Liou ve Tzeng 2007; Liou vd. 2011), metro ile taşımacılık (Awasthi vd., 2011) olarak farklı açılardan ele almıştır. Çalışmalarda çok kriterli karar verme yöntemlerinden bulanık VíKOR (Ay Türkmen ve Bildik, 2015); bulanık TOPSis (Awasthi vd., 2011) kullanılmıştır.

Öte yandan, algılanan hizmet kalitesi kamu taşımacılığında çoğunlukla SERVQUAL ile ölçülmüştür (Randheer vd., 2011; Awasthi vd., 2011; Koçoğlu 2012; Hemedoğlu, 2012). SERVQUAL'ın yanısıra SERVPERF'den yararlanan çalışmalar (Yılmaz, 2012; Yaprakli ve Unalan, 2016) da bulunmaktadır. Awasthi vd. (2011) ise SERVQUAL ve bulanık TOPSiS'den yararlanak melez bir yaklaşımda bulunmuşlardır. Mevcut çalışma da, Ankara ili metro sisteminin algılanan hizmet kalitesini değerlendirmek için Bulanık ELECTRE I yöntemini önermektedir.

\section{VERI VE YÖNTEM}

Karar verme, bir kararın alternatiflerini sıralamada birçok kriteri ve alt kriteri içermekle birlikte en iyi alternatifin seçilmesine yardımcı olur (Saaty,2008). Çok kriterli karar verme yöntemleri, karar vericiler tarafından çeşitli kriterlere bağlı olarak alternatiflerin seçimi veya sıralanmasında kullanılmaktadır. Bulanık ELECTRE I bilginin kısıtlı ve nitel olduğu durumlarda alternatifler arasında tutarlı bir değerlendirme yapılabilmesini sağlayan çok kriterli karar verme yöntemlerinin başında gelmektedir. Bulanık ELECTRE I yöntemi, bulanık set teorisi ile ELECTRE I'in biraraya getirildiği çok kriterli karar verme yöntemidir. Böylelikle, karar vericilerin öznel yargılarından kaynaklanan belirsizliklerle başa çıkmak için dilsel değişkenler, bulanık sayılara dönüştürülerek ifade edilir. Bulanık ELECTRE I, kriterlerin ağırlıkları ve her bir kritere göre alternatiflerin sıralanması bulanık sayılar dikkate alınarak gerçekleştirir. Bu çalışmada dilsel değişkenler, üçgensel bulanık sayılarla temsil edilmektedir. SERVQUAL, algılanan kaliteyi yani tüketicinin bir kurumun genel üstünlüğü hakkında tüketicinin yargısını ölçer. Burada algılanan kalite bir tutum çeşidi olarak tatminle ilişkili fakat eşdeğer değildir, dahası performans algılarına yönelik beklentilerin kıyaslanmasından meydana gelir (Parasuraman vd., 1988). Parasuraman vd. (1985)'ne göre hizmet kalitesi, somut varlıklar, güvenilirlik, cevaplanabilirlik, iletişim, inanırlık, güvenlik, yetkinlik, kibarlık, müşteriyi anlama/bilme, erişim boyutlarından oluşur. Parasuraman vd. (1988), SERVQUAL'in son halinde, müşterilerin herhangi bir kuruma ait algılanan hizmet kalitesini ölçen 22 madde ve somut varlıklar, güvenilirlik, cevaplanabilirlik, garanti, empati biçimindeki beş boyuttan oluşan bir ölçek ortaya koymuşlardır.

\section{Şekil 1: Ankara Metro Hattı Sistemleri}

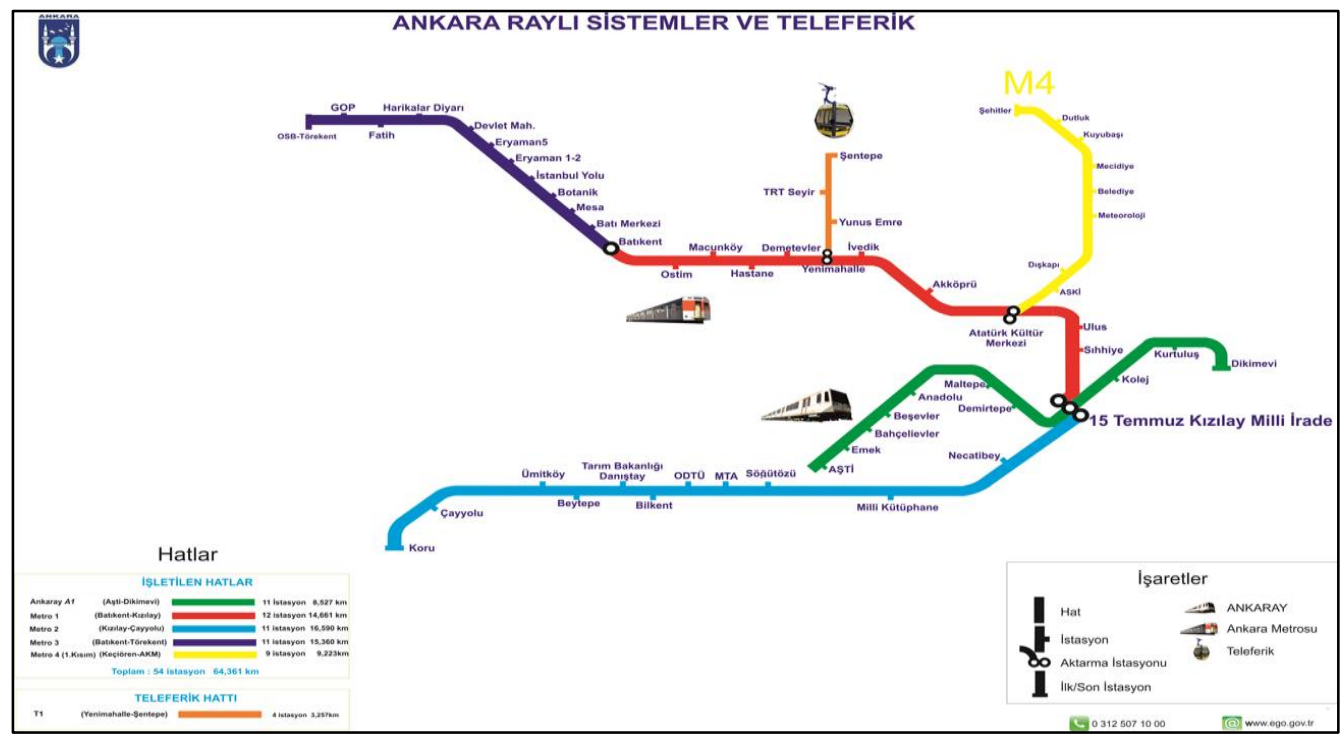

Kaynak: http://www.ego.gov.tr/tr/sayfa/2113/rayli-sistem-hat-harita-ve-semalari 
Mevcut çalışma kamu taşımacılığındaki algılanan hizmet kalitesini belirlemek amacıyla SERVQUAL ve bulanık ELECTRE I yöntemlerini bir araya getiren yeni bir yöntem önermektedir. Uygulamanın ilk aşamasında, Ankara ili metro sisteminin algılanan hizmet kalitesini ölçen verileri toplamak için SERVQUAL yöntemini temel alan bir anket oluşturulmuştur. İkinci aşamada, katılımcılardan alternatifler ve hizmet kalitesi kriterleri ile ilgili görüşleri toplanmıştır. Toplanan veri, Bulanık ELECTRE I yöntemiyle her bir alternatifin performans puanına göre değerlendirilmesi için kullanılmıştır. Mevcut çalışmada, Awasthi vd. (2011)'nin SERVQUAL temelli ölçeğinden faydalanılmıştır. Bulanık ELECTRE I yöntemi ile Ankara metro sisteminde yer alan beş farklı hat değerlendirilmiştir. Söz konusu hatlar; Ankaray (Aşti-Dikimevi); Metro 1 (Batıkent-Kızılay); Metro 2 (Kızılay-Çayyolu); Metro 3 (Batıkent-Törekent); Metro 4 (1. Kısım, Keçiören-AKM)'tür. Ankara metro hattı sistemleri Şekil 1'de görülmektedir. Ankara'daki metro sistemlerinin özelliklerine bakıldığında, Ankaray 8,527 km uzunlukta ve 11 istasyona; M1 14,661 km uzunlukta ve 12 istasyona; M2 16,590 km uzunlukta ve 11 istasyona; M3 15,360 km uzunlukta ve 11 istasyona; M4 9,223 km uzunlukta ve 9 istasyona sahiptir. Ankara'daki metro sistemleri yıllık 131.414 sefer ile toplamda yaklaşık 100 milyon yolcu taşıma kapasitesine erişmektedir.

\section{BULGULAR VE TARTIŞMA}

Mevcut çalışmada sunulan sonuçlar kamu taşımacılı̆ındaki algılanan hizmet kalitesinin belirlenmesi sürecinde önemli etkilere sahiptir. İlk olarak, hizmet çeşitliliği, hizmetlerin sağladığı faydalar, hizmetlerin makul ücretler karşılığı sunulması gibi birçok faktör, algılanan hizmet kalitesini doğrudan etkilemektedir. Kişilerin öznel yargılarını içeren algılanan hizmet kalitesinin belirlenmesi sürecinin doğru bir şekilde değerlendirilmesi oldukça zordur. Bu sebeple, karar vericilerin özenel yargılarını değerlendirmek amacıyla kullanılan geleneksel yöntemler yerine, bulanık sayılarla ifade etmek isabetli sonuçlar doğurmaktadır. İkinci olarak, sosyal fayda sağlayan kamu taşımacılığında algılanan hizmet kalitesi göz önünde bulundurularak alternatifler arasında en iyisinin belirlenmesidir. Yılda milyonlarca yolcuya hizmet sunan kamu taşımacılı̆ının algılanan hizmet kalitesinin belirlenmesi sonucunda daha iyi hizmet kalitesine ulaşmak amacıyla iyileştirmeler yapılabilir. Bu çalışma, Ankara ilinin metro sisteminde yer alan metro hatlarını değerlendirerek yolcuların kişisel yargılarına göre algılanan hizmet kalitesi en iyi hattı belirlemek amacındadır.

Tablo 1: Önerilen Yöntemin Sonuçları

\begin{tabular}{|c|c|c|c|c|c|c|}
\hline & $C(i, j)$ indeks & $C(i, j) \geq \bar{C}$ & $D(i, j)$ indeks & $D(i, j) \geq \bar{D}$ & $p S q$ & Sonuç \\
\hline$C(A, B), D(A, B)$ & 4,153 & - & 8,884 & $\checkmark$ & - & \\
\hline$C(A, C), D(A, C)$ & 1,370 & - & 14 & - & - & \\
\hline$C(A, D), D(A, D)$ & 5,555 & $\checkmark$ & 11,952 & - & - & \\
\hline$C(A, E), D(A, E)$ & 4,005 & - & 14 & - & - & \\
\hline$C(B, A), D(B, A)$ & 7,180 & $\checkmark$ & 14 & - & - & \\
\hline$C(B, C), D(B, C)$ & 1,795 & - & 14 & - & - & \\
\hline$C(B, D), D(B, D)$ & 6,073 & $\checkmark$ & 14 & - & - & \\
\hline$C(B, E), D(B, E)$ & 1,795 & - & 14 & - & - & \\
\hline$C(C, A), D(C, A)$ & 6,013 & $\checkmark$ & 3,113 & $\checkmark$ & $\checkmark$ & C A'ya göre tercih edilir. \\
\hline$C(C, B), D(C, B)$ & 7,658 & $\checkmark$ & 3,288 & $\checkmark$ & $\checkmark$ & C B'ye göre tercih edilir. \\
\hline$C(C, D), D(C, D)$ & 8,236 & $\checkmark$ & 7,335 & $\checkmark$ & $\checkmark$ & C D’ye göre tercih edilir. \\
\hline$C(C, E), D(C, E)$ & 10,150 & $\checkmark$ & 14 & - & - & \\
\hline$C(D, A), D(D, A)$ & 5,412 & $\checkmark$ & 13,637 & - & - & \\
\hline$C(D, B), D(D, B)$ & 3,802 & - & 6,647 & $\checkmark$ & - & \\
\hline$C(D, C), D(D, C)$ & 2,634 & - & 14 & - & - & \\
\hline$C(D, E), D(D, E)$ & 3,547 & - & 14 & - & - & \\
\hline$C(E, A), D(E, A)$ & 6,957 & $\checkmark$ & 10,520 & $\checkmark$ & $\checkmark$ & E A'ya göre tercih edilir. \\
\hline$C(E, B), D(E, B)$ & 9,496 & $\checkmark$ & 9,813 & $\checkmark$ & $\checkmark$ & E B'ye göre tercih edilir. \\
\hline$C(E, C), D(E, C)$ & 3,443 & - & 11,056 & $\checkmark$ & - & \\
\hline
\end{tabular}

Tablo 1, Ankara metro sistemlerinin algılanan hizmet kalitesini belirlemek için önerilen çok kriterli karar verme yönteminin sonuçlarını göstermektedir. Sonuçlara göre, Ankara metro sistemini oluşturan 5 hat içerisinde müşteriler açısından algılanan hizmet kalitesi en yüksek olan hat "M3 (Batıkent-Törekent)" olarak belirlenmiştir. Bu sonucun başlıca sebeplerinden biri, M3 hattının yakın zamanda (2014) hizmete girmesi ve modern tren ve ekipmanlara sahip olması gösterilebilir. Ayrıca Ankara'nın gelişmeye açık bir yerleşim bölgesine gitmesi ve istasyonların merkezi ve ulaşılabilir konumlarda yer alması bir diğer sebep olarak gösterilebilir.

\section{SONUC}

Algılanan hizmet kalitesinin belirlenmesi süreci karar vericilerin öznel yargılarını içermektedir. Geleneksel yöntemlerle öznel yargıları içeren nitel verilerin doğru bir şekilde değerlendirilmesi oldukça zordur. Bu sebeple, belirsizlik içeren nitel ya da dilsel değişkenlerin değerlendirilmesi için bulanık sayı kümelerinden faydalanılır. Bulanık sayı kümeleri dilsel değişkenleri klasik yöntemlerden farklı olarak belli bir üyelik yapısına sahip sayı kümeleri yardımıyla ifade edilmesini sağlar. Bu çalışmada 
kamu taşımacılığındaki algılanan hizmet kalitesinin belirlenmesi için SERVQUAL ile fuzzy ELECTRE I yöntemlerinin bir araya getirildiği bir yöntem önerilmiştir. Önerilen yöntem Ankara ilindeki metro sistemini oluşturan 5 farklı hattın algılanan hizmet kalitesi açısından tercih sırasını belirlemektedir. Sonuçlar Ankara metro sisteminde algılanan hizmet kalitesini belirleyen kriterler açısından M3 hattının ilk sırada olduğunu göstermektedir. Ileriki çalışmalarda bulanık TOPSıS, bulanık VIKOR gibi farklı çok kriterli karar verme yöntemleri ile aynı uygulama yapılabilir.

\section{KAYNAKLAR}

Altuntas, S., Dereli, T., \& Yilmaz, M. K. (2012). Multi-criteria decision making methods based weighted SERVQUAL scales to measure perceived service quality in hospitals: A case study from Turkey. Total Quality Management \& Business Excellence, 23(11-12), p. $1379-1395$.

Ankara Metro Hattı Sistemleri, http://www.ego.gov.tr/tr/sayfa/2113/rayli-sistem-hat-harita-ve-semalari

Awasthi, A., Chauhan, S. S., Omrani, H., \& Panahi, A. (2011). A hybrid approach based on SERVQUAL and fuzzy TOPSIS for evaluating transportation service quality. Computers \& Industrial Engineering, 61(3), p. 637-646.

Ay Türkmen, M., Bildik, T. (2015). Şehirlerarası Yolcu Taşımacılığında Bulanık Vikor Uygulaması, Manas Sosyal Araştırmalar Dergisi, 4(2), p. $1-15$

Brady, M. K., \& Cronin Jr, J. J. (2001). Some new thoughts on conceptualizing perceived service quality: a hierarchical approach. Journal of marketing, 65(3), p. 34-49.

Büyüközkan, G., \& Çifçi, G. (2012). A combined fuzzy AHP and fuzzy TOPSIS based strategic analysis of electronic service quality in healthcare industry. Expert Systems with Applications, 39(3), p. 2341-2354.

de Oña, J., de Oña, R., Eboli, L., \& Mazzulla, G. (2013). Perceived service quality in bus transit service: a structural equation approach. Transport Policy, 29, p. 219-226.

Grönroos, C. (1988). Service quality: The six criteria of good perceived service. Review of business, 9(3), p. 10.

Hemedoglu, E. (2012). Metro hizmetlerinde hizmet kalitesini ölçme: Algilanan hizmet kalitesi ve beklenen hizmet kalitesi üzerine bir karsilastirma. Isletme Iktisadi Enstitüsü Yönetim Dergisi, (72), 25.

Hu, K. C., \& Jen, W. (2006). Passengers' perceived service quality of city buses in Taipei: scale development and measurement. Transport Reviews, 26(5), p. 645-662.

Kocoglu, D. (2012). Seyahat İşletmeciliği Hizmet Kalitesinin Servqual Yöntemi İle Değerlendirilmesi, EKEV Akademi Dergisi, $16(50), 285-297$.

Lai, W. T., \& Chen, C. F. (2011). Behavioral intentions of public transit passengers - The roles of service quality, perceived value, satisfaction and involvement. Transport Policy, 18(2), p. 318-325.

Lee, H., Lee, Y., \& Yoo, D. (2000). The determinants of perceived service quality and its relationship with satisfaction. Journal of services marketing, $14(3)$, p. 217-231.

Liou, J. J., \& Tzeng, G. H. (2007). A non-additive model for evaluating airline service quality. Journal of Air Transport Management, 13(3), p. 131-138.

Liou, J. J., Tsai, C. Y., Lin, R. H., \& Tzeng, G. H. (2011). A modified VIKOR multiple-criteria decision method for improving domestic airlines service quality. Journal of Air Transport Management, 17(2), p. 57-61.

Liu, C. H., Tzeng, G. H., Lee, M. H., \& Lee, P. Y. (2013). Improving metro-airport connection service for tourism development: Using hybrid MCDM models. Tourism Management Perspectives, 6, p. 95-107.

Parasuraman, A., Zeithaml, V. A., \& Berry, L. L. (1985). A conceptual model of service quality and its implications for future research. the Journal of Marketing, p.41-50.

Parasuraman, A., Zeithaml, V. A., \& Berry, L. L. (1988). Servqual: A multiple-item scale for measuring consumer perc. Journal of retailing, 64(1), 12.

Randheer, K., Al-Motawa, A. A., \& Vijay, P. (2011). Measuring commuters' perception on service quality using SERVQUAL in public transportation. International Journal of Marketing Studies, 3(1), p.21-34.

Saaty T. L. (2008). Decision making with the analytic hierarchy process, Int. J. Services Sciences, 1 (1), p. 83-98.

Yilmaz, İ. (2012). Turizm öğrencilerinin karayolu yolcu taşımacılığı hizmetlerine yönelik algılamaları. Anatolia: Turizm Araştırmaları Dergisi, 23(1), 73-85. 